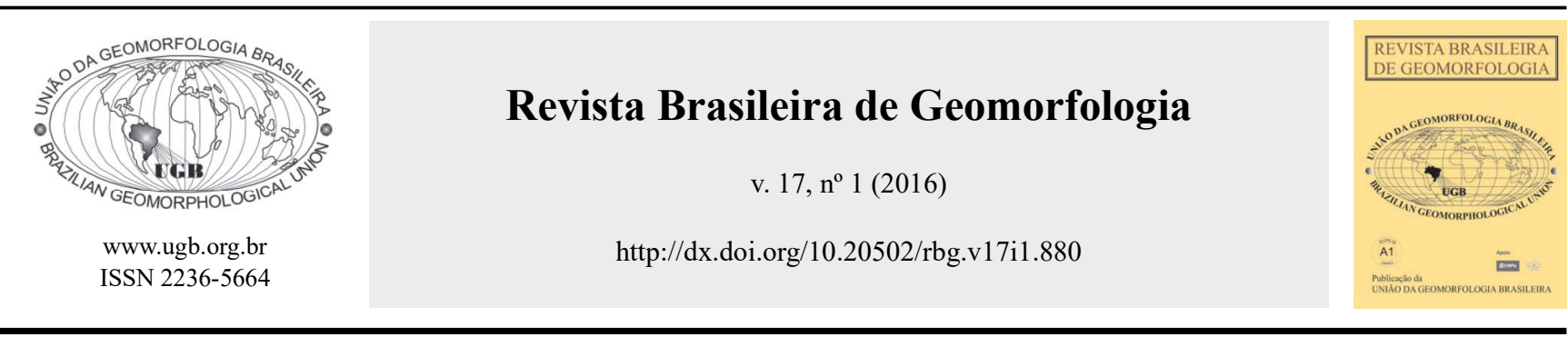

\title{
CARTOGRAFIA GEOLÓGICA E GEOMORFOLÓGICA DE CROSTAS LATERÍTICAS NA PORÇÃO NORTE DO ESTADO DE RONDÔNIA
}

\section{GEOLOGICAL AND GEOMORPHOLOGICAL MAPPING OF LATERITIC CRUSTS IN THE NORTH PORTION OF RONDÔNIA STATE}

\author{
Isabel Leonor Iza Echeverria Herrera \\ Departamento de Geografia, Universidade Federal de Rondônia \\ Br 364, km 9,5, Porto Velho, Rondônia, CEP: 76.801-059, Brasil
}

Email: isaiza@gmail.com

Eliomar Pereira da Silva Filho

Núcleo de Ciências Exatas e da Natureza, Universidade Federal de Rondônia Br 364, km 9,5, Porto Velho, Rondônia, CEP: 76.801-059, Brasil Email:eliomarfilho@uol.com.br

Edgar Romeo Herrera de Figueiredo Iza Instituto de Geociencias, Universidade de Brasilia Campus Universitário Darcy Ribeiro, Brasilia, Distrito Federal, CEP: 70910-900, Brasil Email:edgar.iza@cprm.gov.br

Adriana Maria Coimbra Horbe

Instituto de Geociências, Universidade de Brasília Campus Universitário Darcy Ribeiro, Brasília, Distrito Federal, CEP: 70910-900, Brasil

Email:ahorbe@unb.br

\section{Informações sobre o Artigo \\ Recebido (Received): \\ 23/10/2015 \\ Aceito (Accepted): \\ 28/12/2015}

Palavras-chave:

Platôs; Relevo; Rondônia.

Keywords:

Plateaus; Relief; Rondônia.

\section{Resumo:}

A cartografia geológica e geomorfológica na Amazônia é pouco detalhada, comumente apresenta descrições superficiais e subestimam significativamente as áreas lateríticas. Nesse sentido, no intuito de contribuir para o detalhamento da cartografia na porção norte de Rondônia, recorreu-se a estudos para estabelecer a relação entre a formação de lateritos e os aspectos geomorfológicos. Imagens SRTM, mapas geomorfológicos e geológicos foram integrados e correlacionados para identificar áreas de crostas lateríticas e suas feições geomorfológicas associadas. $\mathrm{Na}$ área de estudo, as crostas lateríticas ocorrem associadas a platôs com altitudes entre 120 e $150 \mathrm{~m}$ e entre 180 e $204 \mathrm{~m}$, todas com declividades inferiores a $2 \%$ e densidade de drenagem muito baixa. Ocupam aproximadamente $264 \mathrm{~km}^{2}$ representando $6,55 \%$ da área de estudo e geram desníveis locais de até 30 $\mathrm{m}$ de altura, especialmente na margem direita do rio Madeira. As crostas lateríticas têm espessuras de até $6 \mathrm{~m}$, são ferruginosas, constituídas principalmente por hematita, goethita, quartzo, raramente caulinita e gibbsita, e apresentam estrutura colunar e textura pisolítica/nodular. A avaliação e posterior integração das imagens 
de radar e de suas principais feições geomorfológicas, assim como as avaliações geológicas, proporcionaram a identificação de novas áreas de ocorrência de crostas lateríticas. Essa integração orientou e facilitou sobremaneira os trabalhos de campo, permitiu a ampliação das áreas de ocorrência de crostas lateríticas e o consequente refinamento dos mapas existentes.

\begin{abstract}
:
The geological and geomorphological mapping in the Amazon is little detailed, commonly presents superficial descriptions and underestimate significantly the lateritic areas. In this sense, in order to contribute with the mapping detailing in the northern portion of Rondônia, it was performed a research to establish the relationship between the laterites formation and the geomorphological aspects. The SRTM images, geomorphological and geological maps were integrated and correlated to identify areas of lateritic crusts and associated geomorphological features. In the area under study, the lateritic crusts occur associated with plateaus, with altitudes between $120 \mathrm{~m}$ and $150 \mathrm{~m}$, and between $180 \mathrm{~m}$ and $204 \mathrm{~m}$, all with slopes lower than $2 \%$ and very low drainage density. The plateaus cover approximately $264 \mathrm{~km}^{2}$, representing $6.55 \%$ of the area, and may generate local differences of altitudes of up to 30 $\mathrm{m}$, especially on the right margin of the rio Madeira. The lateritic crusts are up to $6 \mathrm{~m}$ thick, ferruginous, mainly of hematite, goethite, quartz, rare kaolinite and gibbsite, and show a columnar structure, and pisolithic/nodular texture. The evaluation and integration of radar images and the main geomorphological features, as well as the geological assessment, provided the identification of new areas of occurrence of lateritic crusts. This integration guided and facilitated field work, allowed the increase of areas of occurrence of lateritic crust and the consequent refinement of current maps.
\end{abstract}

\section{Introdução}

As crostas lateríticas ocorrem principalmente ao longo do cinturão intertropical e estão, em grande parte, relacionadas ao Cenozoico (p. ex. LUCAS et al., 1989; NAHON et al., 1989; BOULANGÉ e CARVALHO, 1997; COSTA 1997; HORBE e COSTA 1999; KOTSCHOUBEY et al. 2005, HORBE e COSTA 2005). A região amazônica destaca-se pela significativa ocorrência de crostas lateríticas que, segundo Costa (1991), podem ocorrer nas superfícies rebaixadas ou como platôs ou morros e constitui-se também em uma das últimas fronteiras em termos de cartografia de detalhe, semi-detalhe e de estudos integrados entre os aspectos geomorfológicos e geológicos.

$\mathrm{Na}$ região norte do estado de Rondônia, os mapas geomorfológicos e geológicos atualmente existentes subestimam significativamente as áreas lateríticas. No intuito de contribuir para o detalhamento da cartografia dessa área, executaram-se estudos geomorfológicos integrados com as crostas lateríticas. (THOMAS 1974, PENTEADO 1978, BÜDEL 1982, BIGARELLA et al. 1996 e TAYLOR e EGGLETON 2001).

Thomas (1974) avalia, entre outros temas, os processos físicos e químicos envolvidos na formação das crostas lateríticas e sua relação com os aspectos geomorfológicos, especialmente em ambientes tropicais. $\mathrm{O}$ autor afirma que os lateritos endurecem após a exposição subaérea, e podem resultar na formação de platôs após a atuação de processos erosivos, os quais podem gerar depósitos coluvionares, constituídos por cascalho laterítico e/ou outros produtos de desmantelamento.

Dentro da mesma perspectiva, Penteado (1978) discute a importância dos lateritos e sua afinidade com os processos modeladores da paisagem, sua influência na conservação das antigas superficies de erosão e no desenvolvimento das superfícies aplanadas. A autora observa que as crostas permitem a conservação de velhas superfícies de erosão, desenvolvidas em ambientes tropicais, e ainda favorecem o escoamento superficial impedindo a infiltração, reduzem a erosão mecânica e criam uma paisagem de superfícies aplanadas, seguidas de vertentes côncavas.

A importância geomorfológica das crostas é reafirmada por Büdel (1982), que descreve sua alta resistência à erosão como fator preponderante na inversão topográfica e formação de relevo residual. Neste modelo, as crostas lateríticas são evidenciadas e sua ocorrência é creditada aos processos geológicos associados a evolução do relevo. Para Bigarella et al. (1996) a lateritização é de interesse da geomorfologia, 
especialmente no conhecimento da evolução do relevo, da geologia quando interessada em recursos minerais e da pedologia no estudo do aproveitamento agrícola dos solos.

De maneira análoga, ratificando o papel decisivo da formação das crostas lateríticas no modelamento do relevo, Taylor e Eggleton (2001) demonstram a importância da geomorfologia, destacando os aspectos do clima e da topografia na construção da paisagem. O estudo das crostas lateríticas, segundo os autores, permite compreender a evolução geomorfológica, paleoclimática e pedogenética da paisagem.

Costa (2007) considera como condições mais adequadas para o desenvolvimento de formações lateríticas, a paisagem constituída por relevo topograficamente mais elevado, ligeiramente ondulado, tectonicamente semi-estável, em soerguimento, mas com velocidade em equilíbrio com a taxa de intemperismo tropical. Para o autor, durante o processo de lateritização há uma tendência à peneplanação, o que corrobora a premissa de que as crostas lateríticas estão intimamente relacionadas com as superfícies de aplanamento. Os lateritos são, dessa forma, testemunhos paleoambientais inestimáveis e, de forma geral, constituem valiosos registros geológicos inclusive para estudos paleoclimáticos (COSTA, 2007). O autor afirma, ainda, que extensas crostas lateríticas ferruginosas espalhadas pela Amazônia evidenciam predominância do clima semi-árido e cobertura de savana. Já em outras áreas, caracterizadas por formações lateríticas encimadas por espessos pacotes de Latossolo, prevaleceu longo período de clima tropical quente e úmido, com densa cobertura florestal.

Na Amazônia Ocidental, mais especificamente no estado de Rondônia, foco da presente pesquisa, destacam-se os trabalhos de Guerra (1952 e 1953), que enfatizaram, entre outros aspectos, diversas ocorrências de lateritos nas imediações da cidade de Porto Velho e Guajará-Mirim, abordando de forma superficial os aspectos químicos, mineralógicos e formas de ocorrência. $\mathrm{O}$ autor descreve os aspectos geomorfológicos e de solos de forma generalizada e não relaciona as crostas lateríticas com as formas de relevo ou com as superfícies de aplanamento regional.

McNeil (1972), estudando os solos lateríticos no Sudão e em diversas partes do Brasil, descreveu alguns aspectos relacionados à lateritização na região norte de
Guajará-Mirim/RO, mais especificamente, na região da Colônia do Iata. A autora discute a ocorrência de platôs e o avançado estágio de lateritização da área, destacando os aspectos de pouca fertilidade desses tipos de solos e a falta de planejamento ocorrido no período da colonização. Entretanto, não há discussão sobre a relação das crostas com o contexto geomorfológico regional ou qualquer outra descrição relacionada aos lateritos.

Costa (1991), ao avaliar os aspectos geológicos dos lateritos da Amazônia, indicou, no estado de Rondônia, três alvos de interesse mineral associados ao estanho, manganês e terras raras. Apesar das discussões relacionadas aos aspectos minerais, o autor não relaciona os lateritos com parâmetros geomorfológicos ou topográficos.

Della-Justina (1994), Oliveira e Costa (2006) e Nascimento et al. (2012) caracterizaram resumidamente a lateritização, assim como a natureza e aplicação dos materiais lateríticos na área urbana e entorno de Porto Velho. Os autores destacaram o caráter ferruginoso dos materiais lateríticos e afirmaram se tratarem de perfis imaturos incompletos que ocorrem normalmente associados a relevos jovens, colinosos e platôs.

Castro (2015) abordou o contexto laterítico na Amazônia ocidental com base nos aspectos texturais, mineralógicos e geoquímicos. No estado de Rondônia, o autor mostra que os perfis podem ser completos ou incompletos de acordo com o estágio de evolução/ truncamento e descreve as crostas como constituídas de texturas vermiformes e colunares, localmente pisolíticas, com conteúdo mais significativo de goethita, gibbsita e hematita. Ele afirma ainda que os perfis são remanescentes da fase erosiva associada ao esculpimento da Chapada dos Parecis e a formação do traçado atual do rio Madeira. $\mathrm{O}$ autor conclui que a estrutura dos perfis e a ausência de crosta bauxítica, indicam estrutura típica de perfis pouco evoluídos desenvolvidos a partir do Plio-Pleistoceno, época da segunda fase de lateritização na Amazônia.

Por outro lado, alguns mapeamentos geológicos, regionais ou locais, priorizaram a cartografia das unidades geológicas, como é o caso dos trabalhos de Quadros e Rizzotto (2007) e Oliveira e Filho (2013) em Rondônia. Esses autores constataram a ocorrência de crostas lateríticas ferruginosas em praticamente todo o Estado, assim como depósitos resultantes do seu desmantelamento. Em termos geomorfológicos, 
os três principais mapeamentos executados foram os de Melo et al. (1978), Planafloro (2002) e IBGE (2013). Em todos, as escalas cartográficas finais foram de 1:1.000.000, apesar dos trabalhos de campo terem sido executados na escala de 1:250.000. Os trabalhos supracitados evidenciam, por um lado, a importância do mapeamento das crostas lateríticas e a necessidade de integração com o contexto geomorfológico, e por outro, a limitada quantidade de trabalhos cartográficos em escalas de detalhe e semi-detalhe. Neste contexto, o objetivo deste trabalho foi incrementar a cartografia das unidades geológicas e geomorfológicas com ênfase nas crostas lateríticas na porção norte do estado de Rondônia (Figura 2). São discutidas as principais formas de relevo e as altitudes de ocorrência das crostas lateríticas assim como seu modo de ocorrência, texturas, estruturas e mineralogia.

\section{Materiais e Métodos}

Os trabalhos consideraram a integração e interpretação dos dados geomorfológicos, topográficos e geológicos preexistentes na área de estudo. A base geomorfológica utilizada foi a disponibilizada pela SEDAM (Secretaria Estadual de Desenvolvimento do Meio Ambiente de Rondônia) no Planafloro (Plano Agropecuário e Florestal de Rondônia, 2002) e IBGE (Instituto Brasileiro de Geografia e Estatística, 2013). Os dados altimétricos utilizados foram os do Shuttle Radar Topography Mission (SRTM), que consiste em um sistema de radar especialmente modificado que voou a bordo do Endeavour (ônibus espacial) no ano de 2000. As imagens têm resolução espacial de 90 metros e contribuíram sobremaneira para a interpretação e integração final dos dados. A base cartográfica geológica é a de Quadros e Rizzotto (2007) e Oliveira e Filho (2013) e a partir deles determinou-se os pontos a serem visitados na etapa de campo, em grande parte relacionados às unidades mapeadas como laterítico residual, coberturas detrito-lateríticas, laterítico coluvial e, secundariamente, as chamadas coberturas indiferenciadas.

O passo seguinte consistiu no cruzamento dos mapas geológicos, geomorfológicos e topográficos com o intuito de identificar as altitudes associadas às crostas mapeadas e ao padrão de relevo existente. As áreas com topo plano e com altitudes entre 120 e 204 m constituíram, dessa forma, o principal alvo das investigações em campo, pois apresentaram associação com crostas lateríticas e/ou coberturas sedimentares indiferenciadas e baixa densidade de drenagem.

Os trabalhos de campo consistiram na descrição de perfis lateríticos com suas respectivas características mineralógicas, texturas, modo de ocorrência e aspectos geomorfológicos em 25 locais. Na etapa seguinte, foi gerado o mapa de integração entre áreas de ocorrência de crostas lateríticas e os intervalos altimétricos. Essa integração permitiu a reavaliação dos mapas geomorfológicos e geológico e resultou na sugestão de inclusão das novas áreas com crostas lateríticas em escalas entre 1:100.000 e 1:250.000. A Figura 1 mostra um resumo dos procedimentos realizados neste trabalho.

\section{Contexto Geológico e Geomorfológico Regional}

A região norte do estado de Rondônia está localizada na porção sudoeste do Cráton Amazônico, mais especificamente na província Rondônia-Juruena, que se estende desde o extremo oeste de Rondônia até o alto curso do rio Teles Pires a leste, e é constituída pelos domínios Roosevelt-Juruena e Jamari.

A área em estudo está totalmente inserida no domínio Jamari que ocorre na porção centro-ocidental de Rondônia. O domínio é composto por tonalitos, quartzo-dioritos, granitos, anfibolitos e rochas supracrustais

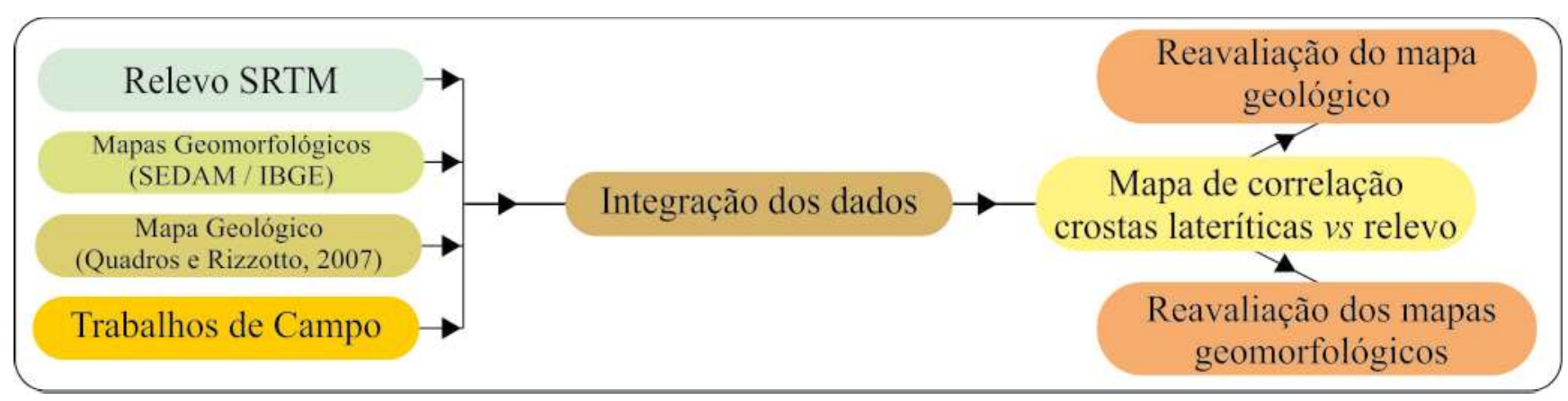

Figura 1 - Fluxograma de procedimentos realizados. 
subordinadas, onde as rochas ortoderivadas possuem idades entre 1,76 e $1,73 \mathrm{Ga}$ e ocorrem como núcleos antigos parcialmente preservados do retrabalhamento crustal resultante de orogenias mais novas (QUADROS e RIZZOTTO, 2007). A unidade mais antiga cartografada é a Suíte Intrusiva Serra da Providência, que é constituída por granitos rapakivi, charnockito, mangerito e rochas máficas associadas. As idades relacionadas aos granitoides variam entre $1606 \pm 24 \mathrm{Ma}(\mathrm{U}-\mathrm{Pb}) \mathrm{e}$ $1532 \pm 5 \mathrm{Ma}(\mathrm{U}-\mathrm{Pb}),($ BETTENCOURT et al. 1999).

Por sua vez, a Suíte Intrusiva Santo Antônio contém três variedades de rochas graníticas com evidências de interação com magmas máficos (PAYOLLA 1994). A unidade é constituída por biotita monzogranito grosso, equigranular a porfirítico e sienogranito com esparsas texturas rapakivi e anti-rapakivi; biotita monzogranito equigranular médio e quartzo monzonito equigranular. Diques pegmatíticos e aplíticos, rochas híbridas e diques de diabásio sin-plutônicos são litotipos associados à suíte. A idade de cristalização da unidade é de $1358 \pm 2 \mathrm{Ma}$ (RIZZOTTO e QUADROS 2005).

A Suíte Intrusiva Teotônio inclui três tipos de rochas que, em ordem decrescente de abundância, compreendem a) microclínio granitos de granulação grossa; b) microclínio granitos bandados de granulação media; c) microclínio-quartzo sienitos e sienogranitos médios a grossos (PAYOLLA 1994). A idade de cristalização para essa unidade é de $1387 \pm 16 \mathrm{Ma}$ (microclínio-granito) (TOSDAL et al. 1995).

A unidade "Terraços Fluviais" é formada por sedimentos mal selecionados representados por cascalho, areia, argila e níveis de turfa, posicionados acima do nível médio das águas dos rios atuais. Os terraços representam antigas planícies de inundação e canais fluviais semelhantes aos atuais, ativos durante períodos quentes do Pleistoceno (QUADROS e RIZZOTTO 2007).

A Formação Rio Madeira engloba os depósitos sedimentares resultantes da formação e evolução do leito ativo, planície de inundação do rio Madeira e do rio Abunã. Essa formação agrupa cascalhos e areias grossas, mal selecionadas, estratificadas e ferruginizadas, bem como argilas maciças a laminadas com restos vegetais (RIZZOTTO e QUADROS 2005; QUADROS et al. 2006; RIZZOTTO et al. 2006).

As coberturas sedimentares indiferenciadas são de idade plio-pleistocênica, interpretadas como de leques aluviais, canais fluviais, planícies de inundação e la- custres, constituídos de uma variedade de materiais que vão desde cascalhos até argilas e incluem fragmentos de crostas e seus produtos de desmantelamento (QUADROS e RIZZOTTO, 2007).

As coberturas detrito-lateríticas compreendem crostas lateríticas ferruginosas, e depósitos detríticos resultantes de seu desmantelamento desenvolvidas, na porção norte do estado de Rondônia preferencialmente sobre as rochas da Suíte Intrusiva Serra da Providência e Suíte Intrusiva Santo Antônio. Os perfis sustentam grande parte do relevo, na forma de baixas mesetas ou platôs, onde a incisão de drenagens foi mais evidente. A crosta tem estrutura colunar e a parte superior está comumente desmantelada. $\mathrm{O}$ horizonte desmantelado pode chegar a medir $50 \mathrm{~cm}$ de espessura. Nas encostas os perfis estão truncados e aflora apenas o horizonte mosqueado parcialmente coberto por colúvios/alúvios areno-argilosos, associados a fragmentos de crosta laterítica, (QUADROS e RIZZOTTO 2007). Além das crostas, ocorrem na unidade sedimentos argilo-arenosos e cascalhos compostos por clastos angulosos de quartzo leitoso e fragmentos nodulares e pisólitos, por vezes cobertos por Latossolo (Amarelo e Vermelho Amarelo). Não há dados geocronológicos em crostas lateríticas no estado de Rondônia, contudo, Costa (1991), Vasconcelos et al., (1996); Ruffet et al. (1996) e Tardy e Roquin (1998), entre outros, afirmam que as crostas lateríticas na Amazônia formaram-se a partir do Cretáceo superior e no Paleoceno, tendo seu máximo no Oligoceno. Horbe (2014), com base em estudos paleomagnéticos em crostas lateríticas na Amazônia, obteve idades entre 10 e $80 \mathrm{Ma}$. A autora afirma que tais idades são compatíveis com os eventos de lateritização da Amazônia e que os resultados contribuem para a delimitação de superfícies de exposição e a correlação com a evolução durante o Cenozoico.

Em termos geomorfológicos, o estado de Rondônia é compartimentado em nove unidades morfoestruturais, (MELO et al. 1978). A área de trabalho está localizada na unidade morfoestrutural denominada de planalto rebaixado da Amazônia (ocidental). Constituise em uma extensa área aplanada, conservada, tendo setores com dissecação suave a muito suave originando interflúvios tabulares, onde se instalaram drenagens cujos rios mais importantes apresentam leitos encaixados (MELO et al. 1978). A altimetria regional varia entre 60 e $250 \mathrm{~m}$ e de modo geral a rede de drenagem secundária apresenta padrão dendrítico com a drenagem 
principal representada pelo rio Madeira. Os principais rios tributários localizados na área são constituintes da bacia do rio Madeira e representados pelos rios Candeias e Jamari.

No mapeamento geomorfológico do estado de Rondônia realizado pelo Planafloro (2002), destacam-se as seguintes unidades geomorfológicas: planícies aluviais e depressões constituídas por terraços e planícies inundáveis, associadas aos principais rios da área. No geral, a área possui relevo plano, dissecação baixa a média e densidade de drenagem baixa a muito baixa. A principal característica desse domínio é o arrasamento generalizado dos materiais de cobertura do cráton, com exposição esporádica das rochas do embasamento, composto por rochas granítico-gnáissicas, (PLANAFLORO, 2002).

Na margem esquerda do rio Madeira destaca-se o terraço fluvial caracterizado por extensa área, enquanto as planícies inundáveis associadas aos rios Candeias e Preto do Candeias, na margem direita do rio Madeira, representam áreas mais restritas inseridas dentro das unidades denudacionais. No limite sudeste há uma área alagada associada ao rio Jamari que ocorre de forma restrita e é em grande parte influenciada pelas águas da barragem de Samuel.

A maior parte da área de estudo está localizada na margem direita do rio Madeira, e é composta por unidades denudacionais, representadas pela superfície de aplanamento (nível II) (PLANAFLORO 2002). É constituída por duas unidades principais; uma de dissecação baixa com nenhum ou esporádicos inselbergs e tors (D2211) na porção central e centro-norte da área, com altitudes relativamente baixas, variando de $70 \mathrm{~m}$ a $120 \mathrm{~m}$; e a segunda de dissecação baixa e muitos tors e hillocks residuais (D2212) na porção centro-leste e centro-oeste da área de estudo, com altitudes variando entre $80 \mathrm{~m}$ e $204 \mathrm{~m}$. Secundariamente, há duas unidades denudacionais presentes: a unidade de dissecação média com nenhum ou esporádicos inselbergs e tors (D2221), com altitudes variando entre $80 \mathrm{~m}$ e $110 \mathrm{~m}$ localizada na porção norte da área de estudo; e a unidade de relevo plano com evidências de superfícies com couraças ferruginosas no limite noroeste, na margem esquerda do rio Madeira, (D2210).

Segundo o IBGE (2013), podem ser identificados três domínios morfoestruturais importantes na área: A) bacias e coberturas sedimentares fanerozoicas repre- sentadas pela Depressão de Porto Velho e Depressão de Ituxi - Jari; B) depósitos sedimentares quaternários representados pela Planície Amazônica; C) crátons neoproterozoicos representados pelo Planalto Residual do Madeira - Ji-Paraná e pela Depressão do Madeira - Ji-Paraná.

A "Depressão de Porto Velho" é caracterizada por dissecação homogênea com feições de topo convexas e tabulares com densidade de drenagem muito baixa a média. Está localizada na margem direita do rio Madeira, na porção central até o leste da área de estudo e é constituída por depósitos sedimentares.

A “Depressão de Ituxi - Jari” é caracterizada por dissecação homogênea com feições de topo convexas e tabulares com densidade de drenagem baixa a média. Está localizada na margem esquerda do rio Madeira e constituída por bacias sedimentares e coberturas inconsolidadas.

A "Planície Amazônica" é composta por acumulações fluviais em terraços e ilhas rochosas que ocorrem ao longo do rio Madeira, e por depósitos sedimentares. Os "Planaltos Residuais do Madeira - Ji-Paraná” estão localizados na porção sudoeste da área e são compostos por áreas mais restritas de dissecação homogênea com feições de topos aguçadas e tabulares, com densidade de drenagem média, e por áreas pediplanadas desnudadas.

Por último, a "Depressão do Madeira - Ji-Paraná" é composta por unidades de dissecação homogênea com feições de topo convexas e tabulares com densidade de drenagem muito baixa. Está localizada no limite sudoeste da área e é representada por depósitos sedimentares.

\section{Crostas Lateríticas e Aspectos Geomorfológicos Locais}

Aárea de estudo é caracterizada por significativo domínio rebaixado com altitudes variando entre $60 \mathrm{e}$ $120 \mathrm{~m}$, contudo, alguns setores apresentam relevo com topo plano, extensões de até $10 \mathrm{~km}$ de comprimento e $8 \mathrm{~km}$ de largura e altitudes entre 120 e $204 \mathrm{~m}$ que representam predominantemente platôs ou mais raramente morros dissecados, representados por hillocks e tors graníticos. As crostas lateríticas estão em grande parte associadas a platôs, ocorrem preferencialmente entre as altitudes 120 e $150 \mathrm{~m}$, mas podem ocorrer nos intervalos entre $180 \mathrm{~m}$ e $204 \mathrm{~m}$ (Figura 2), todas 
com declividades inferiores a $2 \%$ e densidade de drenagem muito baixa. Os afloramentos mais expressivos ocorrem em cortes de estradas, onde são observados horizontes mosqueados com espessuras de até $2 \mathrm{~m}$, crostas com até $4 \mathrm{~m}$ e horizonte desmantelado com espessuras de até $50 \mathrm{~cm}$ (Figura 3). Os platôs têm área total aproximada de $264 \mathrm{~km}^{2}$, representando $6,55 \%$ da área de estudo e com desníveis locais de até $30 \mathrm{~m}$ de altura.

As regiões com altitudes abaixo de $110 \mathrm{~m}$, especialmente aquelas localizadas na margem esquerda do rio Madeira nos limites da cidade de Porto Velho, são caracterizadas por superfícies planas e levemente onduladas com áreas alagadas. Nestas áreas há registros de ocorrência de crostas lateríticas (domínios A211, D2210, D2221, PLANAFLORO (2002), Figura 5), entretanto, serão objeto de estudo de trabalhos futuros e não serão destacadas aqui.

Os perfis lateríticos são classificados como imaturos de acordo com o grau de evolução de Costa (1991). Os níveis de truncamento são variados e podem expor até o horizonte saprolítico.
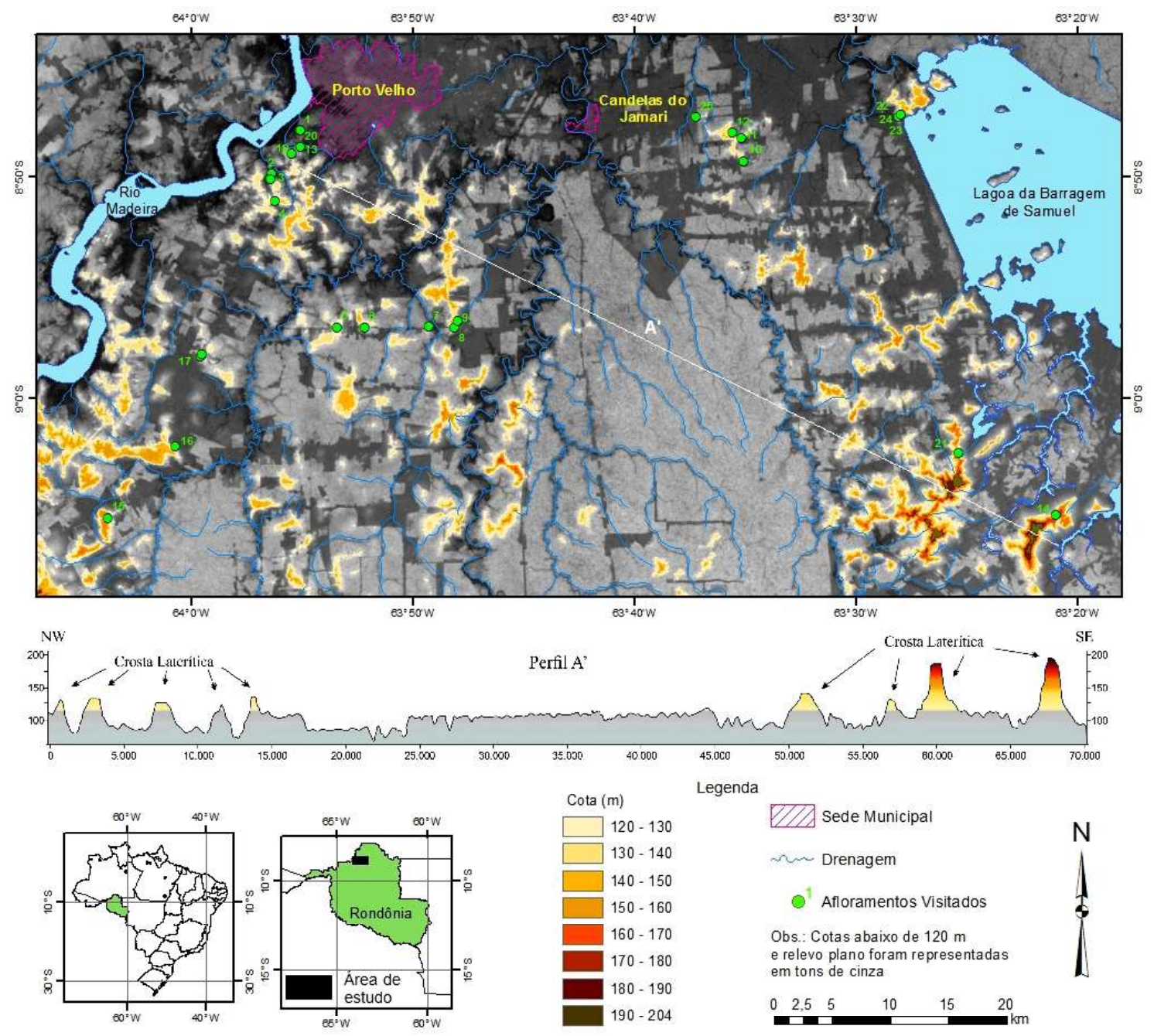

Legenda
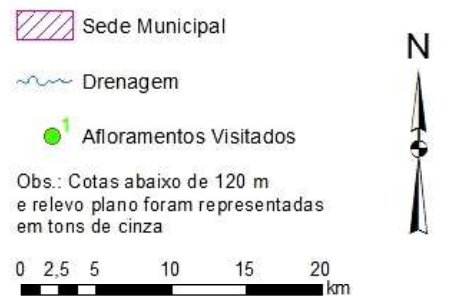

Figura 2 - Áreas com topo plano associadas à ocorrência de crostas lateríticas imaturas. As crostas destacadas estão localizadas essencialmente em dois intervalos: 120 a $150 \mathrm{~m}$ e entre 180 e $204 \mathrm{~m}$.

As crostas têm estruturas colunares verticais a subverticais com composição dominantemente hematítica/ goethítica e subordinadamente cauliníticas, ocorrem quartzo, além de rara gibbsita e magnetita (Figura 4). A porção superior das crostas colunares, pode apresentar textura nodular/pisolítica. Apesar de ocorrer em praticamente toda a área, são mais expressivas na porção sudeste onde ocorrem as rochas da Suíte Intrusiva Serra da Providência, e nas cercanias da cidade de Porto Velho, associadas a Suíte Intrusiva Santo Antônio, podendo 
atingir até $3 \mathrm{~m}$ de espessura. Localmente, as colunas representam canais verticais/subverticais associados a antigas raízes e são comumente preenchidos por nódulos e pisólitos de goethita e de hematita com córtex de goethita, (Figura 3). O topo pode estar desmantelado e recoberto por Latossolo ou por solo orgânico com até $30 \mathrm{~cm}$ de espessura.

Em diversos setores da área, a crosta está desmantelada, de modo que o topo dos perfis é constituído por nódulos, concreções e fragmentos de oxi-hidróxido de ferro em matriz argilosa. Na porção sudoeste da área esses materiais formam uma camada de material incon- solidado, com espessura de até $10 \mathrm{~cm}$, constituindo um depósito superficial relativamente restrito.

As crostas nodulares possuem nódulos com núcleo hematítico preto a marrom escuro e córtex goethítico milimétrico a centimétrico com tons amarelados. Localmente, há nódulos amarelados com $3 \mathrm{~cm}$ de diâmetro formados pela superposição de camadas concêntricas milimétricas de goethita com quartzo e caulinita dispersos em matriz hematítica. Na porção sudoeste da área, as ocorrências de caulinita e gibbsita são mais frequentes e estão associadas às crostas pisolíticas/ nodulares (Figura 4).
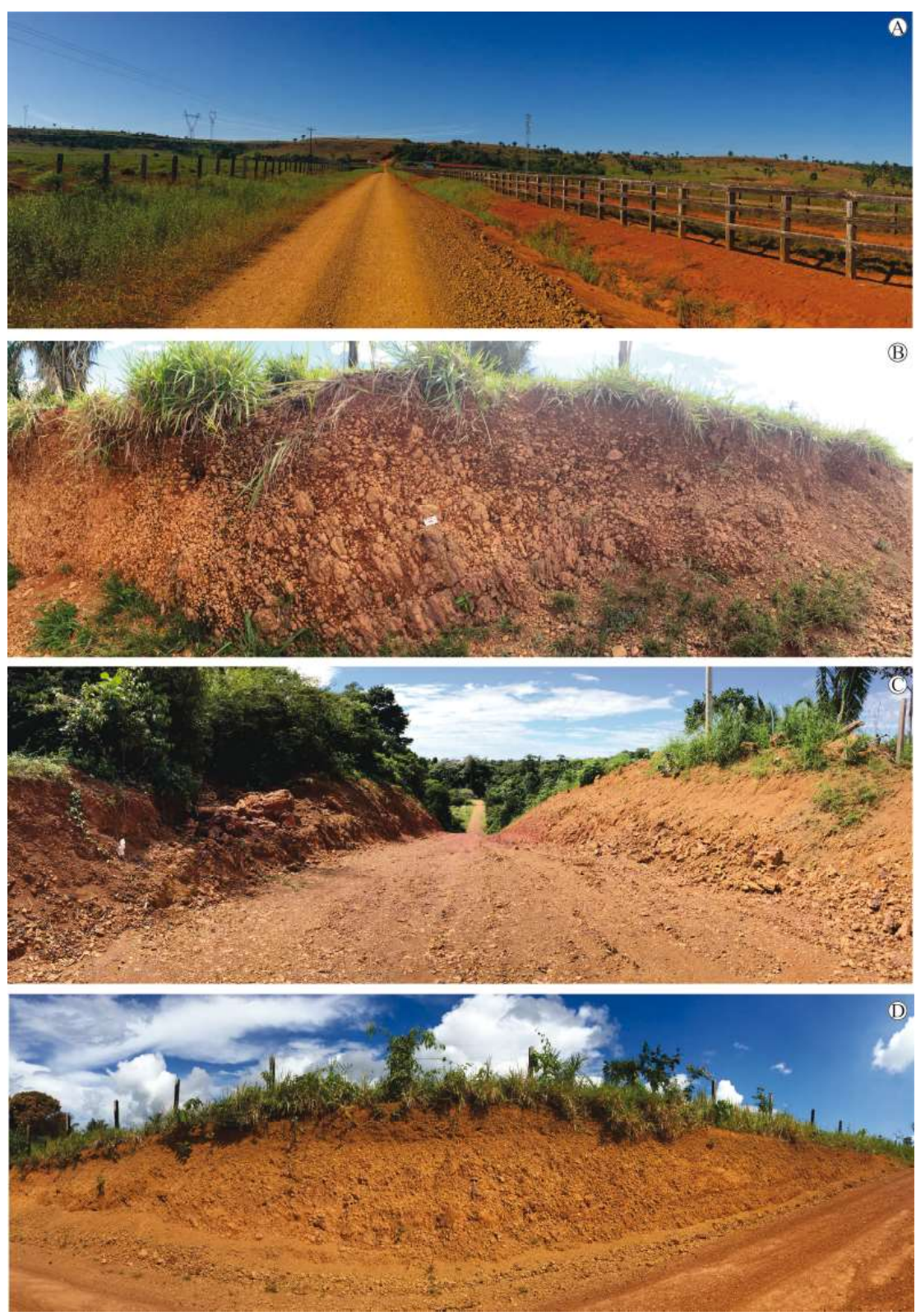

Figura 3 - Perfis destacando a ocorrência de crostas lateríticas ferruginosas na área. A) Relevo rebaixado com platô ao fundo (altitude máxima de $204 \mathrm{~m}$ e desnivel local de até $30 \mathrm{~m}$ ); B) Crostas com estrutura colunar subvertical, altitude de $131 \mathrm{~m}$; C) Crosta laterítica (altitude de $122 \mathrm{~m}$ ) e relevo baixo ao fundo, desnivel de $10 \mathrm{~m}$. D) Exposição das crostas ferruginosas (3 m de espessura), altitude de $120 \mathrm{~m}$. 

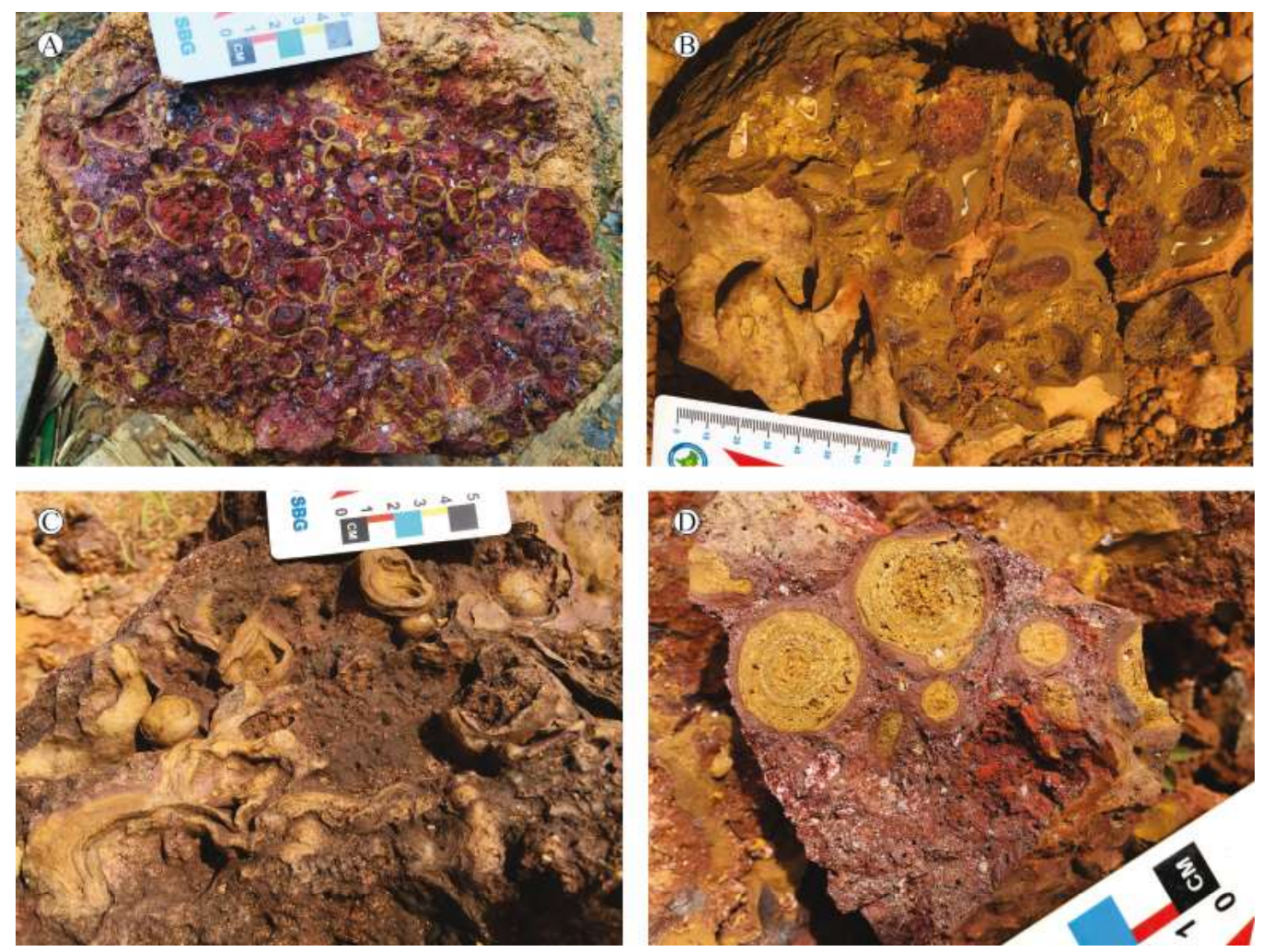

Figura 4 - A e B) Nódulos hematíticos de cor vermelha escura com córtex goethítico amarelado, C) Nódulos amarelados (goethita) evidenciados na parte externa do bloco de crosta laterítica. D) Nódulos goethíticos amarelados, (porção interna) circundados por matriz hematitica avermelhada e porções com caulinita e quartzo.

\section{Discussão dos Dados}

A integração das bases multi-fonte mostrou claramente a associação entre crostas lateríticas e as superfícies de topo plano entre os intervalos de 120$150 \mathrm{~m}$ e $180-204 \mathrm{~m}$. (Figura 2). Contudo, entre as altitudes 90 e $110 \mathrm{~m}$ há registros de crostas lateríticas (DELLA-JUSTINA, 1994; QUADROS e RIZZOTTO, 2007; OLIVEIRA e FILHO 2013) na margem esquerda do rio Madeira e adjacências da cidade de Porto Velho. O modo de ocorrência não favorece a identificação por meio exclusivo da análise do relevo e, portanto, serão alvo de estudos futuros dedicados à margem esquerda do rio Madeira.

Em termos geomorfológicos, existem duas unidades espacialmente significativas, segundo Planafloro (2002): A) D2212, de dissecação baixa e muitos tors e hillocks residuais, que possui altitudes entre 80 e $204 \mathrm{~m}$. É nesta unidade que estão todos os afloramentos visitados de crostas lateríticas associados a platôs. B) D2211, de dissecação baixa e nenhum ou esporádicos inselbergs $e$ tors localizadas em altitudes inferiores a $120 \mathrm{~m}$.
Apesar da ocorrência de crostas lateríticas na unidade D2212, o mapa geomorfológico elaborado pela Planafloro (2002) não as discrimina. Esta discrepância pode estar relacionada às escalas de trabalho utilizadas pelo Planafloro e por este trabalho. A identificação de crostas lateríticas no referido mapa é feita apenas na margem esquerda do rio Madeira na unidade "D2210 - relevo plano com evidências de superfícies com couraças ferruginosas". Dessa forma sugere-se a ampliação desta unidade geomorfológica, exatamente como proposto na Figura 5. O tamanho dos platôs permite sua inclusão em mapas com escalas entre $1.100 .000 \mathrm{e}$ 1:250.000. A existência de dois grandes domínios geomorfológicos na margem direita do rio Madeira, sugere que o processo de erosão regional atuou intensamente, resultando em um domínio arrasado e plano (D2211) e outro residual (D2212) com relevo positivo e topo plano associado às crostas.

Por sua vez, o mapa geomorfológico do IBGE (2013), descreve o domínio "Depressão de Porto Velho" como depósitos sedimentares inconsolidados que constituem formas de relevo de topos tabulares 
conformando rampas suavemente inclinadas esculpidas em coberturas sedimentares com altitudes entre 100 e 150 m (262Dt33). A cartografia dessa unidade geomorfológica coincide parcialmente com os platôs sustentados por crostas lateríticas identificadas neste trabalho. Contudo, diversas áreas cartografadas aqui não foram consideradas pelo mapa do IBGE (2013), fato aparentemente também relacionado à escala e ao objetivo do trabalho. Portanto, como proposto na Figura 6, sugere-se a inclusão de novas áreas que apresentam feições geomorfológicas similares àquelas mapeadas pelo IBGE (topo tabular e densidade de drenagem média a baixa) na unidade 262Dt33, e associadas a crostas ferruginosas identificadas nesse trabalho.

Por sua vez, o termo "depósitos sedimentares inconsolidados" utilizado pelo IBGE é inadequado, pois não há depósitos sedimentares neste domínio geomorfológico, e sim produtos derivados do processo de intemperismo e obviamente não relacionados a processos sedimentares, mas sim a pedogênese. Portanto, sugere-se a mudança da descrição da unidade 262Dt33 para "depósitos residuais associados a processos pedogenéticos que constituem formas de relevo de topos tabulares conformando rampas suavemente inclinadas esculpidas em crostas lateríticas ferruginosas com altitudes entre 120 e 200 m."

Em relação aos aspectos geológicos, o mapeamento realizado por Quadros e Rizzotto (2007) exibe boa correlação com as crostas identificadas neste trabalho. Entretanto, novas áreas na porção sul e sudeste foram identificadas. Nestes setores predominam as unidades "coberturas sedimentares indiferenciadas" e "Suíte Intrusiva Serra da Providência" e subordinadamente outras unidades geológicas descritas no item 3 deste trabalho. Neste sentido, sugere-se a inclusão destas áreas na unidade NQdl - coberturas detrito-lateríticas, como proposto na Figura 7.

As crostas lateríticas e os platôs marcam dois intervalos altimétricos (120 a $150 \mathrm{~m}$ e entre 180 a $204 \mathrm{~m}$ ). Entretanto, as características mineralógicas, estruturais e texturais similares das crostas nesses dois intervalos

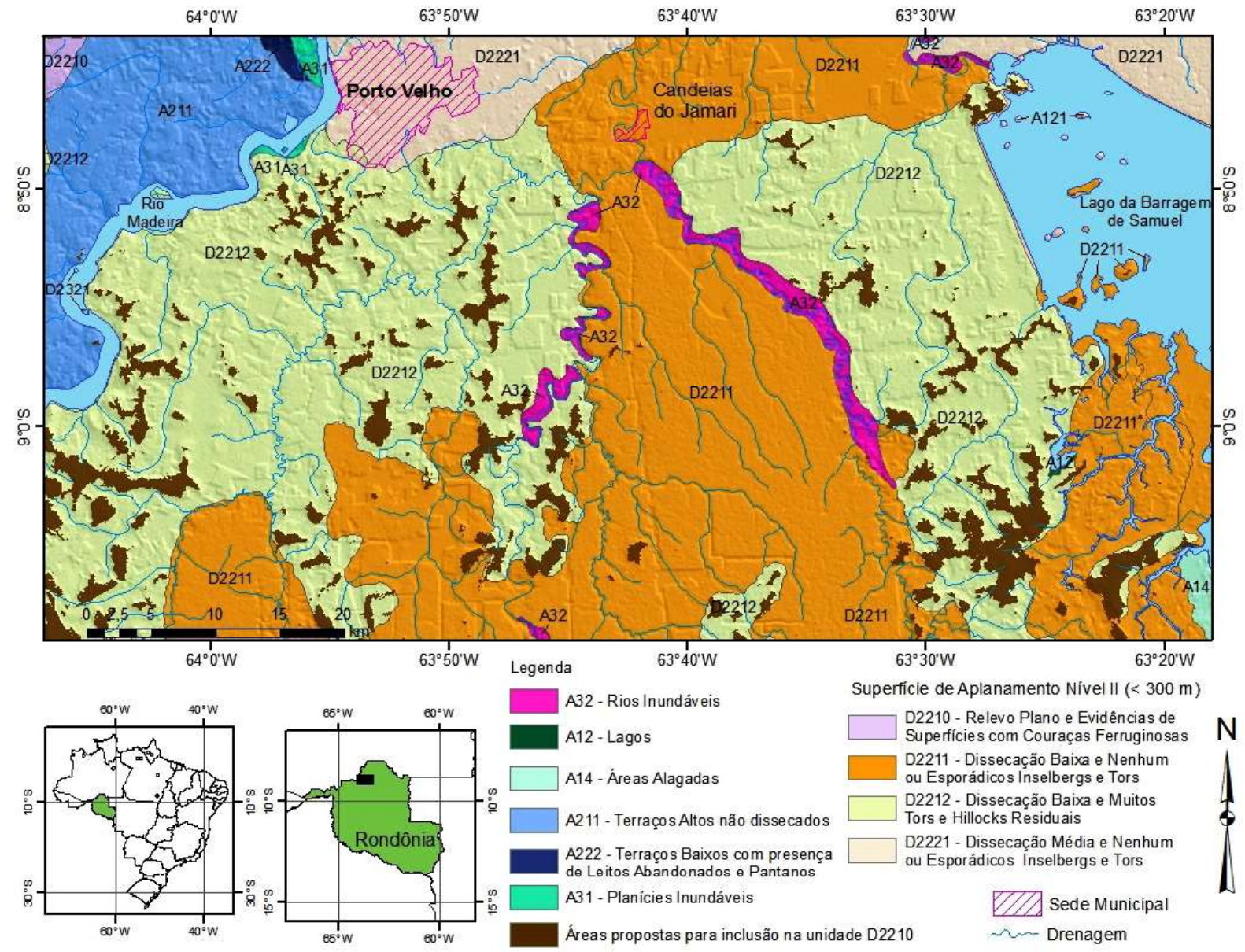

Figura 5 - Mapa geomorfológico proposto com a expansão da unidade geomorfológica "relevo plano com evidências de superficies com couraças ferruginosas", modificado do Planafloro (2002). 
e a correlação com crostas em outros locais da Amazônia (BOULANGÉ e CARVALHO, 1997; COSTA 1997; KOTSCHOUBEY et al. 2005, HORBE 2014), indicam que se formaram na mesma época. Isto sugere efeitos de neotectônica com rebaixamento da superfície inferior, como constatado em outros locais por Guerra (1952 e 1953), Melo et al. (1978), Costa et al. (1996), Souza Filho et al. (1999), Scandolara (1999), Oliveira e Costa (2006) e Litherland e Pitfield (1983). Esta superfície constitui cerca de $77 \%$ da área, está localizada à margem direita do rio Madeira e é representada por extensas áreas aplanadas, correspondentes, em grande parte, às unidades D2221, D2211 e D2212 do mapa do Planafloro (2002). A superfície mais alta, também localizada na margem direita do rio Madeira, constitui aproximadamente $6 \%$ da área e está, em parte, representada pela unidade 262Dt33 do mapa do IBGE (2013). Constitui-se em uma paleosuperfície regional ampla e dissecada que passa atualmente por forte processo de degradação e se correlaciona com os perfis lateríticos mais jovens desenvolvidos no Neógeno na Amazônia. Dados geocronológicos de $\mathrm{U}-\mathrm{Th} / \mathrm{He}$ em goethita podem ajudar a detalhar os aspectos evolutivos, assim como estudos geofísicos gamaespectrométricos $(\mathrm{eTh} / \mathrm{K}, \mathrm{eU} / \mathrm{K})$ podem ser úteis na cartografia das unidades lateríticas (IZA et al. 2016).

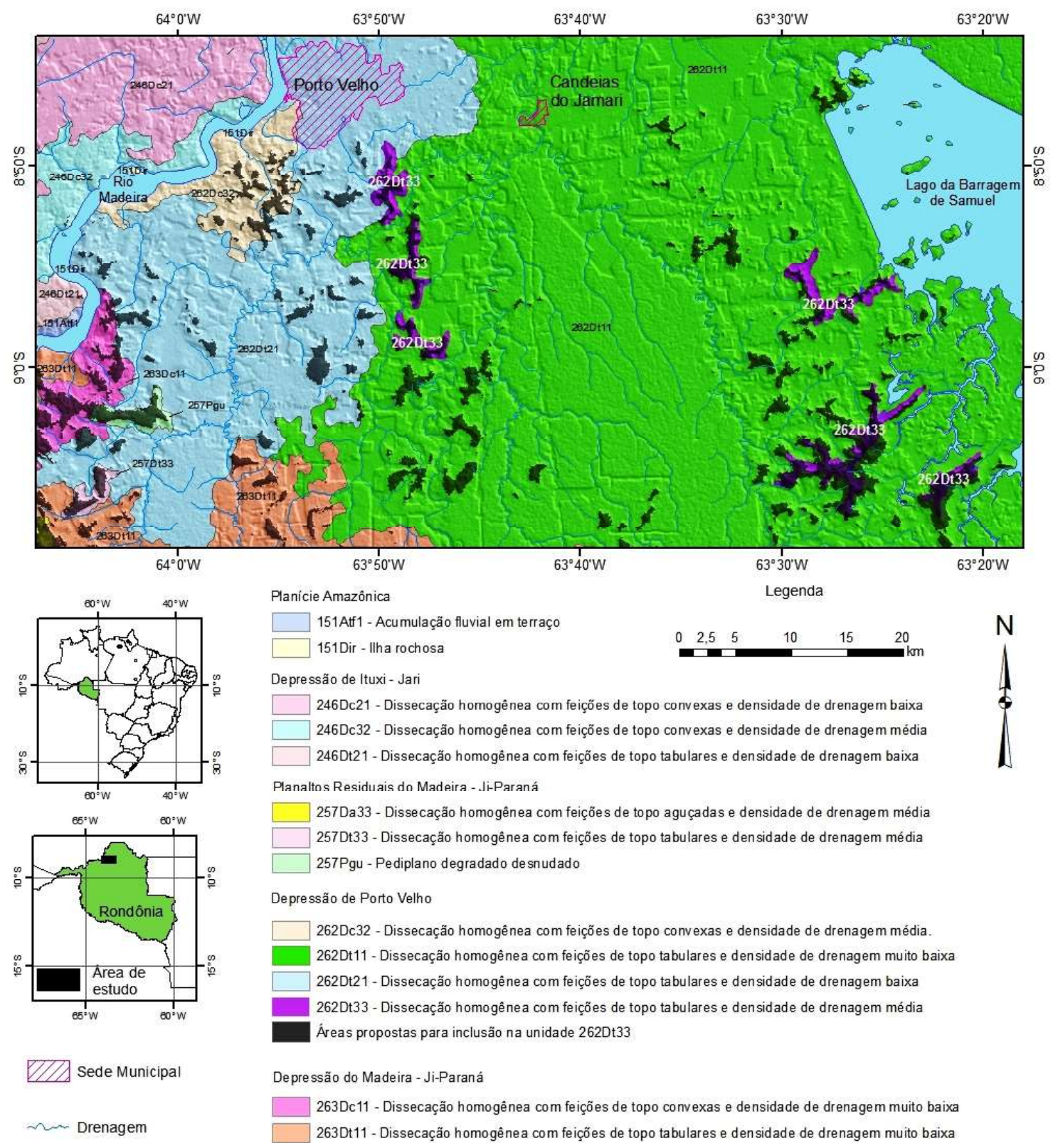

Figura 6 - Mapa geomorfológico com a expansão da unidade geomorfológica “Depressão de Porto Velho”, modificado do IBGE (2013). 


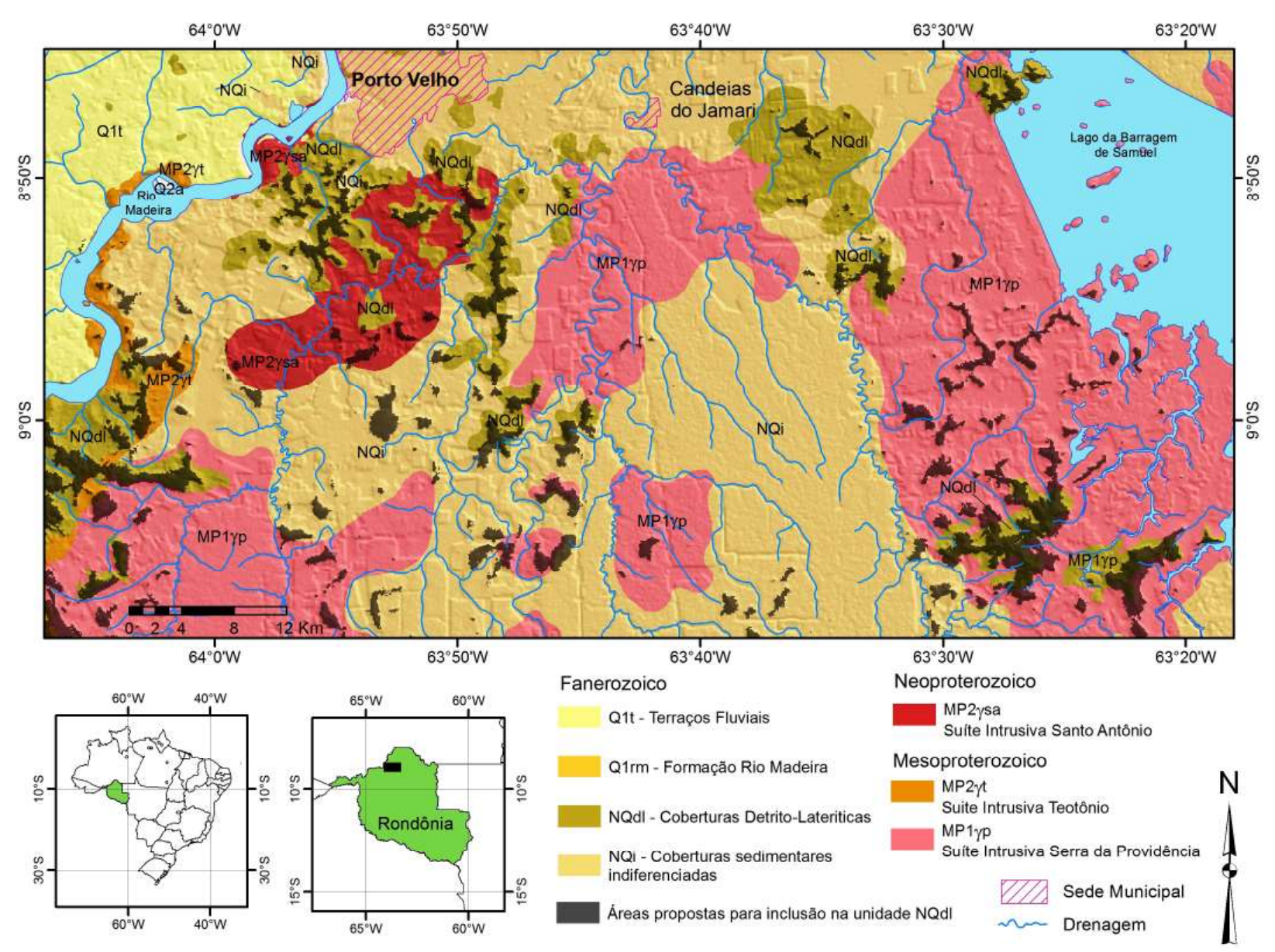

Figura 7 - Mapa geológico com a expansão da unidade "coberturas detrito-laterítica” mostrando a geologia e os principais corpos lateríticos mapeados, modificado de Quadros e Rizzotto (2007).

\section{Considerações Finais}

A identificação, descrição de perfis lateríticos e a correlação com as formas de relevo associadas a dados altimétricos mostraram-se fundamentais para a cartografia de crostas lateríticas e seus produtos de desmantelamento e no aperfeiçoamento dos mapas geológicos e geomorfológicos. Na região amazônica há dificuldade de acesso, pouca informação sobre as crostas e mapeamento com escalas de pouco detalhe. Neste sentido, a integração dos dados mostrou-se eficiente e útil em relação às técnicas convencionais de mapeamento que subestimam as áreas de ocorrência de crostas lateríticas.

As crostas lateríticas e os produtos do seu desmantelamento, além de permitirem reconstruções paleogeográficas e paleoclimáticas, são usados na construção civil como material de aterramento, para construção de estradas, entre outros. Desse modo, a cartografia das crostas e sua relação com os aspectos geomorfológicos podem ser úteis para o planejamento urbano.

A ocorrência de Latossolos associados às crostas é amplamente discutida na Amazônia e a atividade vegetal é apontada como um dos importantes fatores envolvidos. Assim, em alguns setores da área mapeada, por exemplo, aqueles localizados no extremo norte e noroeste, onde predominam solos e não há crostas lateríticas aflorantes, é possível que elas estejam em subsuperfície. Estudos em escala maiores que 1:100.000 são necessários para a identificação das crostas lateríticas na margem esquerda do rio Madeira e podem contribuir com a identificação das paleosuperfícies e com as interpretações relacionadas a neotectônica.

\section{Agradecimentos}

Agradecemos a CAPES pela concessão da bolsa de mestrado ao primeiro autor do trabalho. E.P. Filho e A.M.C. Horbe agradecem ao CNPq pela bolsa de produtividade em pesquisa. 


\section{Referências Bibliográficas}

BETTENCOURT, J.S; TOSDAL, R.M.; LEITE JR., W.B.; PAYOLLA, B.L. Mesoproterozoic rapakivi granites of the Rondônia Tin Province, southwestern border of the Amazonian Craton, Brazil-I. Reconnaissance U-PB geochronology and regional implications. Precambrian Research, v.95, p.41-67, 1999.

BIGARELLA, J. J.; BECKER, R. D.; PASSOS, E.; HERMANN, M. L. P.; MENDONÇA, M.; SANTOS, G. F.; CARVALHO, S. M. C.; COITINHO, J. B. L. Estrutura e Origem das Paisagens Tropicais e Subtropicais. Vol. II. Florianópolis: Editora da UFSC, 1996.

BOUlangé, B.; CARVAlho, A. The bauxite of Porto Trombetas. In. CARVALHOS A., BOULANGÉ B., MELFI A.J., LUCAS Y. (EDS). Brazilian Bauxites, São Paulo: USP/ FAPESP/ORSTOM, p. 55-73. 1997.

BÜDEL, J. Climatic geomorphology. Princeton: Princeton University Press, 1982.

CASTRO, R.T., A lateritização na Amazônia Ocidental: Sul de Roraima e norte e noroeste de Rondônia, Manaus, 2015. Dissertação (Programa de Pós Graduação em Geociências, Universidade Federal do Amazonas.

COSTA, M. L. Aspectos geológicos dos lateritos da Amazônia. Revista Brasileira de Geociências, 21, 146-160, 1991.

COSTA, J.B.S.; BEMERGUY, R.L.; HASUI, Y.; BORGES, M.S; FERREIRA JUNIOR, C.R.P.; BEZERRA, P.E.L; COSTA, M.L.; FERNANDES, J.M.G. Neotectônica Da Região Amazônica: Aspectos Tectônicos, Geomorfológicos E Deposicionais. Geonomos - v.4, n.2, 1996

COSTA, M.L. Lateritization as a major process of ore deposit formation in the Amazon region. Exploration and Mining Geology, v. 6, 79-104. 1997.

COSTA, M.L. da. Introdução ao intemperismo laterítico e à laterização. In: LICHT, O. A. B.; MELLO, C. S. B. de; SILVA, C. R. da (EDS). Prospecção geoquímica: depósitos minerais metálicos, não metálicos, óleo e gás. Rio de Janeiro: SBGq;CPRM. p. 199-244, 2007.

DELLA-JUSTINA, E.E., Retrato Social da Exploração de Recursos Minerais no Município de Porto Velho-Rondônia. O caso dos lateritos, Porto Velho, 1994. Monografia (Especialização em Geografia) - Amazônia, questão Regional e Ambiental, Universidade Federal de Rondônia.

GUERRA, A.T. Formação de lateritos sob a floresta equatorial amazônica (Território Federal do Guaporé). Revista Brasileira de Geografia, v. 4, 33-52, 1952.

GUERRA, A.T. Observações geográficas sobre o Território do Guaporé. Revista Brasileira de Geografia, v.2, 183-302, 1953.

HORBE, A.M.C.; COSTA, M.L Geochemical evolution of a lateritic $\mathrm{Sn}, \mathrm{Zr}, \mathrm{Th}, \mathrm{Nb}, \mathrm{Y}, \mathrm{REE}$ - bearing ore body derived from a pogranite: the case os Pitinga, Amazonas-Brasil. Journal of Geochemical Exploration. v. 66. p. 339-351, 1999.

HORBE, A.M.C.; COSTA, M.L. Lateritic crusts and related soils in eastern Brazilian Amazonia, Geoderma, v. 126. p. 225-239, 2005.

HORBE, A.M.C.; Adriana Maria Coimbra. Idades paleomagnéticas de crostas lateríticas da Amazônia. Boletim do Museu Paraense Emílio Goeldi. Série Ciências Naturais, v. 9, p. 93-104, 2014.

IBGE - Instituto Brasileiro de Geografia e Estatística. Mapas interativos, 2013. Disponível em: <ftp://geoftp.ibge.gov.br/ mapas_interativos/> Acessado em: 20 de junho de 2015.

IZA, E.R.H.F.; HORBE, A.M.C.; SILVA, A.M. Boolean and fuzzy methods for identifying lateritic regoliths in the Brazilian Amazon using gamma-ray spectrometric and topographic data. Geoderma 269, 27-38, 2016.

KOTSCHOUBEY, B.; CALAF, J.M.C.; LOBATO, A.C.C.; LEITE, A.S.; AZEVEDO, C.H.D. Caracterização e gênese dos depósitos de bauxita da Província Bauxitífera de Paragominas, noroeste da bacia do Grajaú, nordeste do Pará/ oeste do Maranhão. In: MARINI O.J.; QUEIROZ E.T.; RAMOS B.V (EDS) Caracterização de depósitos minerais em distritos mineiros da Amazônia. Brasília: DNPM-CT/Mineral-ADIMB, p. 691-782, 2005.

LITHERLAND, M.; PITFIELD, P.E.J. The MesozoicCenozoic history of eastern Bolivia and the recognition of four ages of duricrust. In: MELFI,A.J.; CARVALHO, A. (Eds). Lateritization processes. São Paulo: Instituto Astronômico e Geofísico, 1983.

LUCAS, Y.; KOBILSEK, B; CHAUVEL, A. Structure, genesis and present evolution of Amazonian bauxites developed on sediments. In: INTERNATIONAL COMMITTEE FOR STUDY OF BAUXITE, ALIMUNA AND ALUMINIUM, Poços de Caldas, Anais, 1989, Poços de Caldas: ICSOBA, v. 22: 81-94.

MCNEIL, M., Lateritic Soils in distinct Tropical Environments: Southern Sudan and Brazil. In: FARVAR, M.T.; MILTON, J.P. (EDS), The Careless Technology: Ecology and International Development. New York: The Natural History Press, Doubleday and Co., p 591-608. 1972. 
MELO, D.P.; COSTA, R.C.R.; E NATALI FILHO, T. Geomorfologia da folha SC.20-Porto Velho. In: Projeto RADAMBRASIL. Rio de Janeiro: DNPM, 1978.

NAHON, D.; MELFI, A. J.; CONTE, C. N. Presence d'un vieux système de cuirasses ferrugineuses latéritiques en Amazonie du Sud. As transformation in situ en latosols sous la forêt équatoriale actuelle. Compt. Rend. Acad. Sci., v. 308, p. 755-760. 1989.

NASCIMENTO, T.C.N.; MANIESI, V.; ADAMY, A.; NOGUEIRA, A. A natureza e aplicação dos materiais lateriticos na área urbana e entorno de Porto Velho. Revista Geonorte, Edição Especial, v.2, N.4, p.11 - 19, 2012.

OLIVEIRA, C.E.S.; FILHO, R.S. Materiais de Construção Civil da Folha Porto Velho (SC.20-V-B-V). Porto Velho: CPRM, 2013.

OLIVEIRA, J. G. F.; COSTA, M. L. Caracterização geológica de um perfil laterítico imaturo na região de Porto Velho-Rondônia. In: IX Simpósio de Geologia da Amazônia, 2006, Belém-PA. Trabalhos apresentados, 2006. Belém: SBG-NÚCLEO NORTE, p. 01-04.

PAYOLLA, B.L. As rochas graníticas e sieníticas das cachoeiras Teotônio e Santo Antônio, rio Madeira, Porto Velho, Rondônia: geologia, petrografia e geoquímica. Brasília, 1994. Dissertação, Instituto de Geociências da Universidade de Brasília.

PENTEADO, M. M ${ }^{\mathrm{a}}$. Fundamentos de geomorfologia. $2^{\circ}$ ed. Rio de Janeiro: IBGE, 1978.

PLANO AGROPECUÁRIO E FLORESTAL DE RONDÔNIA, 2002. Disponível em: $<$ http://www.sedam.ro.gov.br/index.php/ component/content/article/109-cogeo/168-acervo-tecnico>. Acessado em 20 de junho de 2015.

QUADROS, M.L. do E.S.; RIZZOTTO, G.J. (Orgs.). Geologia e recursos minerais do Estado de Rondônia: texto explicativo do mapa geológico e de recursos minerais do Estado de Rondônia-escala 1:1.000.000. Porto Velho: CPRM, 2007.

QUADROS, M.L. do E.S.; RIZZOTTO, G.J.; OLIVEIRA, J.G.F. de; CASTRO, J.M.R. de. Depósitos fluviais da Formação Rio Madeira, pleistoceno superior da Bacia do Abunã, Rondônia. In: SIMPÓSIO DE GEOLOGIA DA AMAZÔNIA, 9, Belém. Trabalhos apresentados, 2006, Belém: SBG-Núcleo Norte, 1CD-Rom.

RIZZOTTO, G.J.; QUADROS, M.L do E.S. Geologia do sudoeste do Craton Amazônico. In. HORBE, A.M.C.; SOUZA,
$\mathrm{V}$ da S. (Coords.). Contribuições à geologia da Amazônia, 2005, Belém: SBG-Núcleo Norte, v.4, p 69-84.

RIZZOTTO, G.J.; QUADROS, M.L. do E.S.; OLIVEIRA, J.G. de; CASTRO, J.M. de; LAFON, J.M. Idades PB- dos granitos do setor noroeste do Estado de Rondônia. In: SIMPÓSIO DE GEOLOGIA DA AMAZÔNIA, 9, Belém. Trabalhos apresentados, 2006, Belém: SBG-Núcleo Norte 1CD-Rom.

RUFFET, G.; INNOCENT,C.; MICHARD, A.; FÉRAUD, G.; BEUVAIS,A.; NAHON, D., HAMELIN, B. A geocronological $40 \mathrm{Ar} / 39 \mathrm{Ar}$ and $87 \mathrm{Rb} / 87 \mathrm{Sr}$ study of $\mathrm{K}-\mathrm{Mn}$ oxides from the weathering sequence of Azul, Brasil. Geochimica et cosmochimica Acta, 60: 2219 - 2232, 1996.

SCANDOLARA, J.E. A neotectônica no Estado de Rondônia e adjacências: esboço preliminar e aspectos evolutivos. In: SIMPÓSIO DE GEOLOGIA DA AMAZÔNIA, 6. Manaus, Boletim de Resumos Expandidos, 1999, Manaus: SBG-Núcleo Norte, p.301-304.

SOUZA FILHO, P.W.M.; QUADROS, M.L. do E.S.; SCANDOLARA, J.E.; SILVA FILHO, E.P. da S.; REIS, M.R. Compartimentação morfoestrutural e neotectônica do sistema fluvial Guaporé-Mamoré-Alto Madeira, Rondônia-Brasil. Revista Brasileira de Geociências, v.29, n.4, p.469-476, 1999.

TARDY, Y.; ROQUIN, C. Dérivedês continents: Paléoclimatset alterations tropicales. Orléans: Éditions BRGM, 1998.

TAYLOR, G.; EGGLETON, R. A. Regolith geology and geomorphology. Chichester: John Wiley, 2001.

THOMAS, M. F. Tropical geomorphology: a study of weathering and landform development in warm climates. New York: John Wiley \& Sons, 1974.

TOSDAL, R.M.; BETTENCOURT, J.S.; LEITE Jr., W.B.; PAYOLLA, B.L. Pb isotopic compositions from middle Proterozoic rondonian rapakivi massifs, southwestern margin of the Amazonian Craton, Brazil. In DALL'AGNOL, R.; MACAMBIRA, M.J.B.; COSTI, H.T. (EDS). SYMPOSIUMON RAPAKIVI GRANITES AND RELATED ROCKS, 1, Belém, 1995. Abstracts Volume. Belém: Center for Geosciences. University Federal of Para. p. 78-79.

VASCONCELOS, P.M.; RENNE P.R.; BRIMHALL G. H. \& BECKER, T.A. direct dating of weathering phenomena by 40Ar/39 $\mathrm{Ar}$ and $\mathrm{K}-\mathrm{Ar}$ analysis of supergene $\mathrm{K}-\mathrm{Mn}$ oxides. Geochimica et Cosmochimica Acta, v. 58:1635 - 1666, 1996. 